\title{
DICTIONARY OF ISLAMIC FUNERAL TERMINOLOGY
}

PhD Refik Bulić

\author{
Book review
}

\section{Authors: Ahmet Kasumović and Senaid ef. Feta}

In September 2015, The Institute of Human Rehabilitation, published a book entitled Dictionary of Islamic Funeral Terminology. In the absence of lexicographical material on the otherwise very rich Bosnian language, this dictionary presents only about 3500 burial terms. This dictionary is monolingual, words are accented and very well explained, which is why this book has the characteristics of the lexicon (it interprets customs, habits, obligations, prohibitions, etc.). For a better understanding of the book, it contains color photographs, frequent and numerous comparisons with other religions, and detailed interpretations of particular words or phrases.

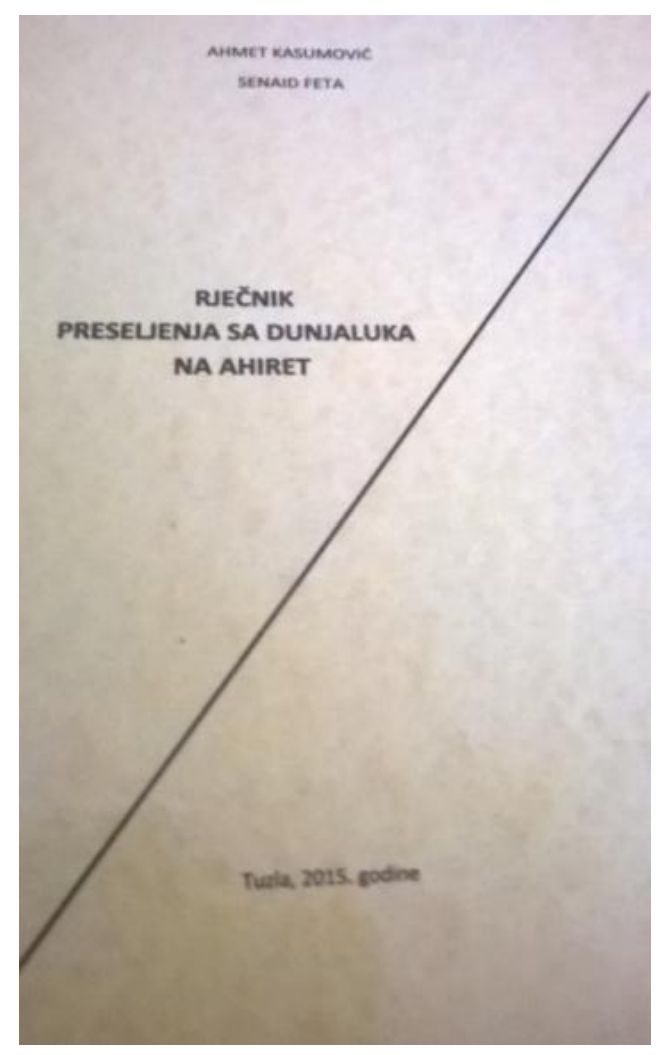

